\title{
EDITORIAL
}

\section{Different Phases of Journalism}

The present era is all revolving around data. Data is around which all reporting, news, research are built up.

The wide range of digital information and statistics being used in journalism provides a depth to the stories and news shared and goes a long way in validating the information shared. In this digital age, data plays a crucial role in catching the eye of the readers and wider acceptance of the information dissemination. Reporting and newswritingget a face-lift when supplemented with statistics and data. Data journalism is being practiced worldwide since long and gradually 'data journalism research' is also strengthening its footprints globally. Additionally, use of social media platforms in reporting is a newer phenomenon. The data harvested through social media platforms can be quite useful for journalistic articles.

The current issue comprises array of papers ranging from No-Mobile-Phobia (Nomophobia) and its impact on investor's decisions, Social Media and Protests Engagement and its linkage with gender based on the famous theory of Planned Behavior and Herd Behavior using PLS-SEM, study on Pilgrimages in Digital Media using qualitative content analysis,linkage of community participationand communication for economic and social empowerment through Microfinance Intervention of women SHG members.
Through the technique of 'Sentiment Analysis and Time-series plots, Use of Twitter as a Customer Service Management Platform by Banks has been emphasized. Then critical need to engage conversations on health ecosystems via mass media platform of cinema in the incident of Bhopal Gas Tragedy in another interesting study followed by a systematic review based comprehensive work on knowledge sharing through virtual community depicting diverse theories on the topic, another Indonesia based study on Data-driven journalism emphasizes on using big data analytics in journalism. Another Indonesian study has given new insights for future climate change communication using social media platforms like Twitter. Highlighting impact of making greater use of Infographics over text during the current COVID - 19 pandemics is a Content Analysis based study on mass media.

\section{Dr. Sumit Narula}

Director and Associate Professor, Amity School of Communication, Amity University Gwalior

\section{Dr. Atul Shiva}

Assistant Professor of Management University School of Business, Chandigarh University, Mohali, India 